\title{
The Anti-Induction for Scientific Realism
}

\author{
Seungbae Park \\ (Ulsan National Institute of Science and Technology)
}

\begin{abstract}
In contemporary philosophy of science, the no-miracles argument and the pessimistic induction are regarded as the strongest arguments for and against scientific realism, respectively. In this paper, I construct a new argument for scientific realism which I call the anti-induction for scientific realism. It holds that, since past theories were false, present theories are true. I provide an example from the history of science to show that antiinductions sometimes work in science. The anti-induction for scientific realism has several advantages over the no-miracles argument as a positive argument for scientific realism.
\end{abstract}

\section{Keywords}

Anti-Induction, No-Miracles Argument, Pessimistic Induction, Scientific Realism

\section{Introduction}

In contemporary philosophy of science, the no-miracles argument (Putnam 1975, 73) and the pessimistic induction (Laudan 1977, 126; Putnam 1978, 25) are regarded as the strongest arguments for and against scientific realism, respectively. The no-miracles argument says roughly that it would be a miracle that most successful theories are completely false, so most successful theories are approximately true. ${ }^{1}$ The pessimistic induction says that, since past theories were false, it is likely that present theories are also false. ${ }^{2}$ For the past several decades, these two arguments dominated the debate over what epistemic attitude we should take towards our best theories (Worrall 1989, 101, 2011; Psillos 1996; Magnus and Callender 2004, 322; Sankey 2017, 201).

The aim of this paper is to defend a new argument for realism that I call the antiinduction for realism. It asserts that, since past theories were false, present theories are true. I proceed as follows. In Section 2, I provide an example from the history of science to show that anti-inductions sometimes work in science. In Section 3, I unpack the anti-induction for realism, explicating how it differs from the pessimistic induction against realism, and displaying its several advantages over the no-miracles argument as an alternative positive argument for realism. I also argue that antirealists can construct an anti-induction to circumvent the pessimistic induction against an antirealist position. In Section 4, I reply to two possible objections against the anti-induction for realism. At the end, I will have demonstrated that the anti-induction is superior to the no-miracles argument as an argument for realism.

\section{Historical Episode}

A historical episode recounted by Carl Hempel (1966, 3-6) is useful to illustrate that antiinductions sometimes work in science and to highlight the opposing views of pessimists and anti-inductivists. A Hungarian physician, Ignaz Semmelweis (1818-1865), was appointed to

\footnotetext{
1 I drop the qualifiers 'most,' 'completely', and 'approximately' from now on to save space.

${ }^{2}$ I drop the phrase 'it is likely' from now on for the sake of brevity.
} 
the medical staff in the Vienna General Hospital in 1846. He was distressed to learn that about $10 \%$ of the women in the first maternity division died of childbed fever, while about $2 \%$ of the women in the second maternity division died of childbed fever. He postulated and painstakingly tested one by one the following six hypotheses that might account for the discrepancy: (i) miasmas in the air caused puerperal fever, (ii) the first division was overcrowded, (iii) medical students examined women roughly in the first division, (iv) the sight of a priest and his attendant had a terrifying psychological impact on the women in the first division, (v) the women in the first division delivered lying on their backs while the women in the second division delivered on their sides, and (vi) cadaverous materials on the medical students' hands were responsible for the high mortality rate. He eliminated the first five hypotheses before he arrived at the sixth hypothesis. The sixth hypothesis was successful in dramatically reducing the high mortality rate of the first maternity division.

Imagine that both pessimists and anti-inductivists had been watching Semmelweis as he was about to put the sixth hypothesis to the test. They would have made opposite predictions about the experimental outcome of the sixth hypothesis. Pessimists would have predicted that, since the five previous hypotheses failed their tests, the sixth hypothesis would also fail its test. By contrast, anti-inductivists would have predicted that, since the five hypotheses failed their tests, the sixth hypothesis would pass its test. Semmelweis performed the experiment of instituting a hand-washing regimen, thereby confirming the antiinductivists' prediction and disconfirming the pessimists' prediction.

How could the pessimists and anti-inductivists draw the opposite conclusions from the same premise that the five previous hypotheses had failed their tests? The pessimists and antiinductivists operated on opposite principles. The pessimists operated on what David Hume $(1978,89)$ called the uniformity principle that an unobserved instance resembles observed instances. Without that principle, the pessimists' conclusion would not follow from the premise. In contrast, the anti-inductivists operated on what Park (2017a, 213) calls the disuniformity principle that an unobserved instance differs from observed instances. Without that principle, the anti-inductivists' conclusion would not follow from the premise.

There are multiple anti-inductions, just as there are multiple pessimistic inductions. ${ }^{3}$ Anti-inductivists run different anti-inductions in different contexts, just as pessimists run different pessimistic inductions in different contexts. In the context of predicting the experimental outcome of Semmelweis's sixth hypothesis, anti-inductivists construct the antiinduction that since the five previous hypotheses failed their tests, the sixth hypothesis will pass its test, while pessimists construct the pessimistic induction that since the five previous hypotheses failed their tests, the sixth hypothesis will also fail its test. In the context of predicting the truth-value of Semmelweis's sixth hypothesis, anti-inductivists advance the anti-induction that since the first five hypotheses were false, the sixth hypothesis is true, while pessimists advance the pessimistic induction that since the first five hypotheses were false, the sixth hypothesis is also false. Anti-inductivists and pessimists formulate different anti-inductions and different pessimistic inductions, respectively, regarding different targets. The bottom line, however, is that the disuniformity principle underlies all anti-inductions, whereas the uniformity principle underlies all pessimistic inductions, whatever their targets might be.

\footnotetext{
3 See Park (2017a) for the pessimistic inductions against scientific theories, scientists, realists, antirealist theories, antirealists, and pessimists. See also Park (2018a) for a pessimistic induction from the old pessimistic induction (Laudan 1977; Putnam 1978) to the new pessimistic induction (Stanford 2006).
} 
Scientific progress requires at least occasional uses of the disuniformity principle (Park 2017a, 216-217). Suppose that scientists underwent some trials and errors in their attempts to arrive at true or successful hypotheses. If they used the uniformity principle, i.e., if they were pessimists, they would believe that nothing follows but more and more trials and errors. By contrast, if they used the disuniformity principle, i.e., if they were anti-inductivists, they would believe that achievements follow trials and errors. If past scientists had used only the uniformity principle to assess the prospects of their research projects, they would have achieved fewer true or successful hypotheses. As a result, we might still believe that the Earth is at the center of the universe, and we might still use horses instead of cars and airplanes as means of transportation. The list of such examples can be extended ad nauseam. Scientists are anti-inductivists when they achieve something after a series of trials and errors, whether those trials and errors concern experimental outcomes or the truth-values of hypotheses. Hence, anti-inductions sometimes work in science.

Pessimists might object that anti-induction is simply absurd. Suppose that antiinductivists and inductivists watch a stone being thrown upwards and falling down over and over. Anti-inductivists predict that the stone will float in the sky, and they continue to make false predictions. By contrast, inductivists predict that it will fall to the ground, and they continue to make true predictions. Thus, anti-induction is unreasonable, whereas induction is reasonable. We should use the uniformity principle to predict future events.

The preceding objection, however, commits the straw-man fallacy. My position is not that scientists and philosophers should be anti-inductivists in all contexts, but that they should be anti-inductivists in some contexts and inductivists in other contexts. The fact that inductions work in science at some times does not refute my position that anti-inductions work in science at other times.

Pessimists might now object that it was fallacious to reason that since the five previous hypotheses failed tests, the sixth hypothesis would pass the test. How could the failures of the five hypotheses be the evidence for expecting the success of the sixth hypothesis? Antiinductivists should have justified the disuniformity principle independently of anti-induction. In the absence of independent justification, it was merely epistemic luck that anti-inductivists made the true prediction that the sixth hypothesis would be successful. They were not entitled at all to make the true prediction.

A similar objection, however, can be raised against pessimists. Imagine that Semmelweis was about to test the fifth hypothesis, and that pessimists predicted that it would fail the test because its four forerunners had failed. Their prediction was true. It was, however, merely epistemic luck that they made the true prediction. How could the failures of the four hypotheses be the evidence for expecting the failure of the fifth hypothesis? Pessimists should have justified the uniformity principle independently of induction. In the absence of independent justification, pessimists were not entitled at all to make the true prediction.

Pessimists might now argue that my foregoing reply is straightforwardly fallacious; it is merely a tu quoque argument. That is, they might say that it is wrong for me to argue that an argument is good by saying that it is similar to a bad argument.

Let me point out, however, that it is costly for pessimists to accuse me of committing the fallacy of $t u$ quoque. The accusation implies that the pessimistic induction is fallacious. And if the pessimistic induction is fallacious, the strongest threat to realism evaporates. It is not clear whether pessimists would be willing to go this far. In my view, they would stake out the following new position instead.

The new pessimist position holds that we should be anti-inductivists when predicting experimental outcomes, but should be pessimists when predicting truth-values of hypotheses. Also, scientists should keep entertaining and testing further hypotheses, despite repeated 
failures, not with a view to finding true hypotheses, but with a view to finding successful hypotheses. Under this new position, pessimists could predict that Semmelweis's sixth hypothesis would pass the test on the grounds that its five predecessors failed, but could also predict that the sixth hypothesis was false on the grounds that its five predecessors were false. Also, pessimists can argue that Semmelweis should have kept thinking up and testing further hypotheses, until he arrived at a successful hypothesis, one that would help to bring down the high mortality rate in the first maternity division. This new pessimist position comports with the fact that false theories were successful in the history of science.

A double standard, however, is involved in this new pessimist position. Why is it that we should be anti-inductivists, when predicting experimental outcomes, but should be pessimists when predicting the truth-values of hypotheses? The new pessimist position contrasts with the anti-inductivist position, which is free from any double standard. It maintains that we should consistently use the disuniformity principle to predict both the truthvalues and experimental outcomes of hypotheses. The anti-inductivist position is better than the pessimist position, ceteris paribus, because the principle of economy favors the former over the latter. It appears that pessimists should consistently use the uniformity principle to predict experimental outcomes as well as truth-values of hypotheses in order to be equal to anti-inductivists in terms of simplicity. Alternatively, they should provide an argument to justify their different predictions of experimental outcomes and truth-values of hypotheses.

Pessimists might try to justify that double standard as follows. There are infinitely many unconceived hypotheses that compete, for example, with Semmelweis's sixth hypothesis. All of them can explain why the mortality rate of the first division was higher than that of the second division. Since the number of such alternatives is infinitely large, scientists can never reach and recognize the true hypothesis, and anti-inductivists will perpetually make only false predictions about the truth-values of successive hypotheses. By contrast, there is only a finite number of experimental failures. Therefore, we should be pessimists when predicting truth-values of hypotheses, but anti-inductivists when predicting experimental outcomes.

The preceding suggestion, however, is problematic. If five eliminated hypotheses constitute an inductive rationale for thinking that there are infinitely many unconceived alternative hypotheses, five corresponding experimental failures also constitute an inductive rationale for thinking that there are infinitely many unperformed experimental failures. There is no reason to suppose that the former inductive rationale is stronger than the latter. If it is a hasty generalization to infer that there are infinitely many unperformed experimental failures on the basis of the five experimental failures, so is it a hasty generalization to infer that there are infinitely many unconceived alternative hypotheses on the basis of the five false hypotheses. These two inferences stand or fall together. Consequently, if pessimists predict that the sixth hypothesis will be false on the grounds that there are infinitely many unconceived alternatives, they should also predict that the sixth hypothesis will fail the experimental test on the grounds that there are infinitely many unperformed experimental failures. It follows that pessimists have no good reason to apply the uniformity principle to predict the truth-value of the sixth hypothesis while applying the disuniformity principle to predict the experimental outcome of the sixth hypothesis. The double standard remains unjustified.

Pessimists might now argue that we should use the disuniformity principle when predicting experimental outcomes because they are ascertainable by observation, but that we should use the uniformity principle when predicting the truth-values of hypotheses because they are not ascertainable by observation. On this account, we should be anti-inductivists 
when assessing scientists' inferences concerning observables, but we should be pessimists when assessing scientists' inferences concerning unobservables.

The preceding argument, although tempting to pessimists, begs the question against anti-inductivists. It is under dispute between pessimists and anti-inductivists whether we should use the disuniformity principle to assess scientists' inferences about unobservables. Pessimists contend that we should use the uniformity principle, while anti-inductivists contend that we should also use the disuniformity principle. But the pessimists' argument assumes the very point under dispute in order to justify itself, i.e., pessimists state in effect that we should use the uniformity principle to assess scientists' inferences about unobservables because the inferences are about unobservables. Such a circular argument does not adequately answer the question: Why should we use the uniformity principle to assess scientists' inferences about unobservables? Pessimists need to justify the use of the uniformity principle independently of whether scientists' inferences are about observables or unobservables. In the absence of such justification, we should choose the anti-inductivist position over the pessimist position, because the principle of economy enjoins us to do so, as noted above.

\section{The Anti-Induction for Realism and Antirealism}

Let me now turn to the pessimistic induction that, since past theories were false, present theories are also false. The strength of the pessimistic induction is proportional to the number of past theories (Park 2016, 838). The more past theories were false, the stronger the inductive rationale is for thinking that present theories are false. What if present theories are discarded in the future? The inductive rationale will become stronger for thinking that future theories will be false. Thus, the downfall of current theories will only reinforce pessimists' conviction that future theories will be false.

Compare the foregoing pessimistic induction with the anti-induction that, since past theories were false, present theories are true. As with the pessimistic induction, the strength of the anti-induction is proportional to the number of past theories. The more past theories were false, the stronger the anti-inductive rationale is for thinking that present theories are true. What if present theories are abandoned in the future? The anti-inductive rationale will become stronger for thinking that future theories will be true. Thus, the demise of present theories will only reinforce anti-inductivists' belief that future theories will be true.

As an alternative argument for realism, the anti-induction differs from the no-miracles argument in the following important respect. The no-miracles argument relies on inference to the best explanation (IBE) to justify realism, claiming that realism best explains the success of science. In contrast, the anti-induction does not rely on IBE. It relies instead on the history of science. Its premise is that past theories were false. Thus, the no-miracles argument and the anti-induction use radically different methods to arrive at realism.

The anti-induction has several advantages over the no-miracles argument. First, the nomiracles argument is subject to Larry Laudan's $(1981,45)$ and Arthur Fine's $(1991,82)$ criticism. They argue that the no-miracles argument begs the question against critics of IBE. The critics do not regard IBE as a reliable rule of inference, but the no-miracles argument uses IBE to justify realism. The critics would not be impressed by such a circular argument. The anti-induction, by contrast, is not susceptible to the objection of circularity because it relies on the history of science rather than on IBE to justify realism.

Second, the no-miracles argument attempts to justify realism by explaining the success of science. Consequently, it is vulnerable to the antirealist critique that the success of science can be explained without invoking truth. There are nine antirealist explanations of the success of science in the literature (Park 2014). Proponents of the no-miracles argument bear the 
burden of showing that the realist explanation is superior to all the antirealist alternatives. In contrast, anti-inductivists bear no such a burden, because the anti-induction does not attempt to arrive at realism by explaining the success of science.

Third, Laudan's (1981) list of past theories poses a threat to the no-miracles argument, but not to the anti-induction. The list is as follows:

\section{Laudan's List}

- the crystalline spheres of ancient and medieval astronomy;

- the humoral theory of medicine;

- the effluvial theory of static electricity;

- "catastrophist" geology, with its commitment to a universal (Noachian) deluge;

- the phlogiston theory of chemistry;

- the caloric theory of heat;

- the vibratory theory of heat;

- the vital force theories of physiology;

- the electromagnetic aether;

- the optical aether;

- the theory of circular inertia;

- theories of spontaneous generation. (Laudan 1981, 33)

The past theories on this list are all counterexamples to the no-miracles argument's conclusion that successful theories are true (Park 2011, 76-77). By contrast, they are the very fuel for the anti-inductivist conclusion that present theories are true. Without the list, the premise of the anti-induction that past theories were false is merely an unjustified assumption.

Jarrett Leplin (1997) and Juha Saatsi (2009, 358) argue that the past theories on Laudan's list, although successful, did not make novel predictions. Timothy Lyons (2003, 898-899) retorts that "there have been numerous examples of novel success from theories that are clearly false by present lights," providing a list of fourteen such past theories, such as Fresnel's wave theory of light and Bohr's 1913 theory of the atom. Unlike Leplin and Saatsi, anti-inductivists welcome Laudan's and Lyons's lists, taking them as the evidence for the premise of the anti-induction. The longer the lists, the more convincing the anti-induction is.

The preceding discussion shows that the anti-induction departs radically from the traditional view that the history of science should have been stable in order for realism to be tenable. Under the traditional framework, selectivists make efforts to show that past science was more stable than pessimists depict. They distinguish between stable and unstable parts of a past theory, and argue that the past theories on Laudan's list were not completely false but rather approximately true, on the grounds that the stable parts of the past theories are retained in present theories. Selectivism is embraced by many prestigious philosophers, such as John Worrall (1989), Philip Kitcher (1993, 140-149), Stathis Psillos (1999, Chapters 5 and 6), Pierre Cruse and David Papineau (2002), Patrick Enfield (2008), David Harker (2008), Stathis Psillos (2009), Saatsi (2009), and Peter Vickers (2017). Like pessimists, selectivists operate under the uniformity principle, holding that present theories will be discarded just as past theories were discarded (Park 2017c, 65; 2017d, 102; 2017d, 98-99; 2018b, 60-61; Stanford 2018, 79). Unlike both selectivists and pessimists, however, anti-inductivists operate under the disuniformity principle, asserting that unstable past science is the positive evidence for realism.

Let me now turn to an anti-induction for antirealism. Bas van Fraassen $(1985,294)$ and K. Brad Wray $(2008,321,2012,376)$ contend that successful theories are empirically adequate. Mario Alai takes constructive empiricism to be claiming that "all we need to believe is that a theory is empirically adequate" (2017: 21). Park (2001, 78), Marc Lange 
(2002, 282), and Lyons (2003, 898) point out, however, that the pessimistic induction, if correct, has a devastating consequence on the antirealist position that successful theories are empirically adequate. Past theories clashed with anomalies, phenomena that they could not accommodate. So they were empirically inadequate, although they were successful. It follows that present theories are also empirically inadequate, although they are successful. Thus, antirealists who believe successful theories are empirically adequate have every reason to refute the pessimistic induction.

The antirealists can defuse the pessimistic induction by an appeal to the anti-induction that, since past theories were empirically inadequate, present theories are empirically adequate. They do not need to give up antirealism, even if it transpires that present theories are empirically inadequate. In such cases, the degree of their belief that future theories will be empirically adequate will only grow stronger, given that the anti-inductive rationale for their position grows stronger. Thus, the anti-induction entitles the antirealists to believe that present theories are empirically adequate.

\section{Objections and Replies}

I have claimed above that the more past theories were false, the stronger is the anti-inductive rationale for thinking that present theories are true. This contention, pessimists might object, presupposes that the number of unconceived alternatives is finite. Suppose, for example, that there are ten unconceived alternatives in the possibility space of alternatives, and that one of them is true. As scientists eliminate more and more alternatives, they get closer and closer to the true theory, and the probability increases that the next theory will be true. But what if the number of unconceived alternatives is infinite? Removing a finite number of alternatives in the possibility space of alternatives will in no way increase the probability of finding the true theory.

This pessimistic objection to the anti-induction, however, has a disastrous consequence on the pessimistic induction. As noted earlier, the pessimistic induction claims that the more past theories were false, the stronger the inductive rationale is for thinking that present theories are false. On this account, present theories are more likely to be false than past theories, because present theories are preceded by more false theories than past theories. If, however, there are infinitely many unconceived alternatives, past and present theories are all $0 \%$ probable, and hence past theories cannot be no more probable than present theories (Park $(2016,840)$.

Let me turn to another possible objection from pessimists. Wray (2013) explores a way around the realist objection (Leplin 1997, 141; Doppelt 2007, 111, 2011, 2014; Saatsi 2009, 358; Devitt 2011, 292; Fahrbach 2011a, 2011b, 1290; Park 2011, 80; Mizrahi 2013) that present theories are more successful than past theories. He asks us to imagine that past realists, who might have existed in, say, the nineteenth century, believed their accepted theories merited their doxastic commitment, although their rejected theories did not, because the former were more successful than the latter. However, in retrospect we now know that past realists were wrong, i.e., that their retained theories were false, just as their discarded theories were false. We can extrapolate the epistemic fate of present realists from that of past realists. Specifically, present realists believe that present theories merit their doxastic commitment, although past theories did not, on the grounds that the former are more successful than the latter, but "our scientific offspring will look back at our theories with the same disdain we have for the theories of our predecessors" (Wray 2013, 4327).

It is clear how Wray would criticize the anti-induction for realism. Imagine that past anti-inductivists, who might have existed in, say, the nineteenth century, believed that since their discarded theories were false, their retained theories were true. We now know, however, 
that the past anti-inductivists were wrong, i.e., that their accepted theories were false, just as their rejected theories were false. Analogously, present anti-inductivists claim that, since past theories were false, present theories are true. Our descendants, however, will see in retrospect that present anti-inductivists are wrong, i.e., that present theories are false, just as past theories were false. Consequently, it does not matter whether present theories are better than past theories. The uniformity principle still applies, and it is wrong for anti-inductivists to say that since past theories were false, present theories are true.

It is also clear, however, how present anti-inductivists would reply to the foregoing possible objection from Wray. Present anti-inductivists would insist that precisely because past anti-inductivists were wrong about their retained theories, present anti-inductivists are right about present theories. The more often past anti-inductivists were wrong, the more likely it is that present anti-inductivists are right. Thus, past anti-inductivists' mistakes help, rather than hurt, the anti-inductivist position. To emphasize, it is of no use for pessimists to bring up past mistakes. They only stimulate the anti-inductivist spirit.

\section{Conclusion}

The pessimistic induction against realism holds that, since past theories were false, present theories are also false. In contrast, the anti-induction for realism holds that, since past theories were false, present theories are true. The pessimistic induction operates under the uniformity principle, whereas the anti-induction operates under the disuniformity principle. The antiinduction has several advantages over the no-miracles argument as a positive argument for realism, the most important being that it is immune to challenges based upon the history of science.

The anti-induction might still strike many readers as absurd. Let me remind them, however, that scientists are anti-inductivists when they eliminate unsuccessful hypotheses one by one in the hope that they will someday come by a successful hypothesis. You are also an anti-inductivist when you endure present trials and errors in your daily life in the hope that you will someday achieve something after the trials and errors. If you believe that failure is the mother of success, you are an anti-inductivist, relying on the disuniformity principle; if you believe that failure is the mother of more failure, you are a pessimist, relying on the uniformity principle.

Finally, I do not claim that we should always be anti-inductivists. I concede that this is an absurd position. I insist, however, that it is also an absurd position that we should always be inductivists, or that we should never be anti-inductivists. Accordingly, I claim instead that we should at some times be anti-inductivists and should at other times be inductivists. It is a matter of future research to provide a philosophical account of when we should be inductivists and when we should be anti-inductivists.

\section{References}

Alai, Mario 2017. "The Debates on Scientific Realism Today: Knowledge and Objectivity in Science." In: Varieties of Scientific Realism: Objectivity and Truth in Science, edited by Evandro Agazzi, Switzerland: Springer International Publishing, 19-47.

Cruse, Pierre and David Papineau 2002. "Scientific Realism without Reference." In: The Problem of Realism, edited by Michele Marsonet, Aldershot, U.K.: Ashgate, 174-189.

Devitt, Michael 2011. "Are Unconceived Alternatives a Problem for Scientific Realism?" Journal for General Philosophy of Science 42, 285-293. 
Doppelt, Gerald 2011. "From Standard Scientific Realism and Structural Realism to Best Current Theory Realism.” Journal for General Philosophy of Science 42 (2), 295-316.

2007. "Reconstructing Scientific Realism to Rebut the Pessimistic Meta-induction." Philosophy of Science 74 (1), 96-118.

--------- 2014. "Best Theory Scientific Realism.” European Journal for Philosophy of Science 4 (2), 271-291.

Enfield, Patrick 2008. "P. Kyle Stanford, Exceeding Our Grasp: Science, History, and the Problem of Unconceived Alternatives." The British Journal for the Philosophy of Science 59 (4), 881-895.

Fahrbach, Ludwig 2011a. "How the Growth of Science Ends Theory Change." Synthese 180 (2), 139-155.

-------- 2011b. "Theory Change and Degrees of Success." Philosophy of Science 78 (5), $1283-1292$.

Fine, Arthur 1991. "Piecemeal Realism.” Philosophical Studies 61 (1-2), 79-96.

Harker, David 2008. "P. Kyle Stanford, Exceeding Our Grasp: Science, History, and the Problem of Unconceived Alternatives." Philosophy of Science 75 (2), 251-253.

Hempel, Carl 1966. Philosophy of Natural Science. New Jersey: Prentice-Hall.

Hume, David 1978. A Treatise of Human Nature. L. A. Selby-Bigge and P. H. Nidditch (eds.), Oxford University Press.

Kitcher, Philip 1993. The Advancement of Science: Science without Legend, Objectivity without Illusion. New York: Oxford University Press.

Lange, Marc 2002. "Baseball, Pessimistic Inductions and the Turnover Fallacy." Analysis 62 (4), 2881-2885.

Laudan, Larry 1977. Progress and Its Problems: Towards a Theory of Scientific Growth. California: University of California Press. 1981. “A Confutation of Convergent Realism.” Philosophy of Science 48 (1), 19-49.

Leplin, Jarrett 1997. A Novel Defense of Scientific Realism. New York: Oxford University Press.

Lyons, Timothy 2003. "Explaining the Success of a Scientific Theory." Philosophy of Science 70 (5), 891-901.

Magnus, P. D. and Craig Callender 2004. "Realist Ennui and the Base Rate Fallacy." Philosophy of Science 71 (3), 320-338. 
Mizrahi, Moti 2013. "The Pessimistic Induction: A Bad Argument Gone Too Far." Synthese 190 (15), 3209-3226.

Park, Seungbae 2001. Scientific Realism vs. Scientific Antirealism. Ph.D. Dissertation, University of Arizona.

--------- 2011. “A Confutation of the Pessimistic Induction.” Journal for General Philosophy of Science 42 (1), 75-84.

-------- 2014. “A Pessimistic Induction against Scientific Antirealism.” Organon F 21 (1), $3-21$.

2016. "Refutations of the Two Pessimistic Inductions." Philosophia 44 (3), 835-844.

2017a. "The Uniformity Principle vs. the Disuniformity Principle.” Acta Analytica $32(2), 213-222$.

2017b. "Why Should We Be Pessimistic about Antirealists and Pessimists?" Foundations of Science 22 (3), 613-625.

2017c. "On Treating Past and Present Scientific Theories Differently.” Kriterion 31 (1), 63-75.

2017d. "Selective Realism vs. Individual Realism for Scientific Creativity." Creativity Studies 10 (1), 97-107.

--------- 2018a. “The Grand Pessimistic Induction.” Review of Contemporary Philosophy 17, $7-19$.

2018b. "Justifying the Special Theory of Relativity with Unconceived Methods." Axiomathes 28 (1), 53-62.

Psillos, Stathis 1996. "Scientific Realism and the 'Pessimistic Induction'." Philosophy of Science 63 (Proceedings), 306-314.

1999. Scientific Realism: How Science Tracks Truth. New York: Routledge.

2009. “Grasping at Realist Straws.” Review Symposium, Metascience 18, 363-370.

Putnam, Hilary 1975. Mathematics, Matter and Method (Philosophical Papers, vol. 1), Cambridge: Cambridge University Press.

1978. Meaning and the Moral Sciences. London: Routledge \& K. Paul.

Saatsi, Juha 2009. "Grasping at Realist Straws.” Review Symposium, Metascience 18, 355362. 
Sankey, Howard 2017. "Realism, Progress and the Historical Turn." Foundations of Science 22 (1), 201-214.

Stanford, P. Kyle 2006. Exceeding Our Grasp: Science, History, and the Problem of Unconceived Alternatives. Oxford: Oxford University Press.

2018. “A Fond Farewell to 'Approximate Truth'?”, Spontaneous Generations: A Journal for the History and Philosophy of Science 9 (1), 78-91.

van Fraassen, Bas 1985. "Empiricism in the Philosophy of Science" In Images of Science, edited by Paul Churchland and Clifford Hooker, Chicago: University of Chicago Press, 245308.

Vickers, Peter 2017. "Understanding the Selective Realist Defence against the PMI." Synthese. 194 (9), 3221-3232.

Worrall, John 1989. "Structural Realism: The Best of Both Worlds." Dialectica 43, 99-124.

2011. "Miracles and Structural Realism." In: Structural Realism: Structure, Object, and Causality, edited by Elaine Landry and Dean Rickless, Springer Netherlands, 77-98.

Wray, K. Brad 2008. "The Argument from Underconsideration as Grounds for Anti-Realism: A Defence.” International Studies in the Philosophy of Science 22 (3), 317-326.

2012. “Epistemic Privilege and the Success of Science.” Noûs 46 (3), 375-385.

2013. "The Pessimistic Induction and the Exponential Growth of Science Reassessed." Synthese 190 (18), 4321-4330. 